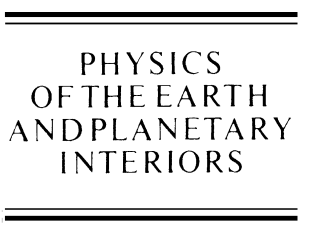

Physics of the Earth and Planetary Interiors 123 (2001) 45-63

www.elsevier.com/locate/pepi

\title{
On the observed annual gravity variation and the effect of sea surface height variations
}

\author{
Tadahiro Sato $^{\mathrm{a}, *}$, Yoichi Fukuda ${ }^{\mathrm{b}}$, Yuichi Aoyama ${ }^{\mathrm{c}, 1}$, Herbert McQueen $^{\mathrm{d}}$, \\ Kazuo Shibuya ${ }^{\mathrm{e}}$, Yoshiaki Tamura ${ }^{\mathrm{a}}$, Kazuyoshi Asari ${ }^{\mathrm{a}}$, Masatsugu Ooe ${ }^{\mathrm{a}}$ \\ ${ }^{a}$ National Astronomical Observatory, Hoshigaoka 2-12, Mizusawa 023-0861, Japan \\ ${ }^{\mathrm{b}}$ Department of Geophysics, Graduate School of Science, Kyoto University, Oiwake-cho, Kitashirakawa, Sakyou-ku, Kyoto 606-8502, Japan \\ ${ }^{c}$ The Graduate University for Advanced Studies, Hoshigaoka 2-12, Mizusawa 023-0861, Japan \\ ${ }^{\mathrm{d}}$ Research School of Earth Science, The Australian National University, Canberra, ACT 0200, Australia \\ ${ }^{\mathrm{e}}$ National Institute of Polar Research, Kaga 1-9-10, Itabashi-ku, Tokyo 173-8515, Japan
}

Received 25 January 2000; received in revised form 2 October 2000; accepted 4 November 2000

\begin{abstract}
Based on two datasets of sea surface height (SSH) variations, the Parallel Ocean Climate Model (POCM) [J. Geophys. Res. 101 (C10) (1996) 25779] and the TOPEX/POSEIDON (T/P) altimeter, we have analyzed the effect of SSH variations on gravity observations. For this purpose, we first estimated the steric component of SSH variations which we characterized by a thermal steric coefficient relating the sea surface temperature (SST) to SSH. The steric coefficient was estimated on each ocean mesh by assuming a simple linear relation ship between the time variations in the SSH and SST fields. We obtained a value of $0.60 \times 10^{-2} \mathrm{~m} /{ }^{\circ} \mathrm{C}$ averaged over the central parts of the Pacific and Atlantic Oceans. We then estimated the annual gravity change by calculating the effects of the solid tide, ocean tide, polar motion and SSH variations. The predicted values at the three observation sites (i.e. Esashi in Japan, Canberra in Australia and Syowa Station in Antarctica) were compared with the actual data obtained from the superconducting gravimeters installed at these three sites. The results of the comparison indicate that the predictions agree with the observations within $20 \%$ in amplitude (i.e. within $0.2 \mu \mathrm{Gal}$, where $1 \mu \mathrm{Gal}=1 \times 10^{-8} \mathrm{~ms}^{-2}$ ) and $20^{\circ}$ in phase at each observation site for both SSH datasets of the POCM and T/P. We have also tested other values for the steric coefficient, i.e. $0.0 \times 10^{-2}$ and $1.0 \times 10^{-2} \mathrm{~m} /{ }^{\circ} \mathrm{C}$, but find that the fit-to-gravity observations made at the mid-latitudes is clearly better at $0.60 \times 10^{-2} \mathrm{~m} /{ }^{\circ} \mathrm{C}$. It is noted that our gravity observations point to a value of steric coefficient similar to that independently determined from the relationship between the SSH and SST data. We have also tried to investigate the effects of SSH on the gravity observations in other frequency bands. Among these effects, one of the interesting results is the gravity changes induced by ENSO-like ocean oscillations. Our computations suggest that the oscillations contribute 2-3 $\mu$ Gal in peak-to-peak amplitude to gravity variations in the equatorial Pacific at the maximum. (C) 2001 Elsevier Science B.V. All rights reserved.
\end{abstract}

Keywords: Annual gravity change; Polar motion effect; Effect of the sea surface height (SSH) variations; Steric effect; Superconducting gravimeter

\footnotetext{
* Corresponding author. Tel.: +81-197-22-7137; fax: $+81-197-22-2715$.

E-mail address: tsato@miz.nao.ac.jp (T. Sato).

${ }^{1}$ Present address: Radio Science Center for Space and Atmosphere, Kyoto University, Gokasho, Uji, Kyoto 611-0011, Japan.
}

\section{Introduction}

Thanks to precise space geodetic observation techniques such as very long baseline interferometer (VLBI) and global positioning system (GPS), the 
temporal changes of earth orientation parameters (EOP) can now be observed with an accuracy of 1 mas $(1$ mas $=1$ milli arc second $)$ or better. If we can observe the earth's response to EOP changes at a similar relative accuracy, they give us very important and accurate information about the nature of earth's interior in a frequency band much lower than the seismic and short-period tidal bands. At these lower frequencies, however, there are only few kinds of observational data available to measure the earth's response. Among these, the gravity data obtained from a superconducting gravimeter (SG; Goodkind, 1999) network such as 'Global Geodynamics Project' (GGP; Crossley et al., 1999) may be one of the best candidates to use for this purpose.

Accordingly, some challenging studies using SG data have already been conducted. Sato et al. (1997) analyzed the amplitude and phase of the polar motion effect on gravity using 2-year SG data obtained at Syowa Station, Antarctica, and obtained a value of about 20 days for the time lag of the gravity data against the polar motion data served by International Earth Rotation Service (IERS). ${ }^{2}$ The length of the SG data, however, was too short to safely separate the two dominant periodic components in the polar motion, i.e. annual (12 months) and Chandler (14 months) periods. Recently, Loyer et al. (1999) analyzed the 8-year SG time series obtained from Strasbourg in France, and estimated the amplitude factor and phase of gravity changes at the Chandler period. Since the parameters estimated by them are dependent on the number of waves considered in the analysis, they obtained phases distributed within a range of $9-22^{\circ}$, corresponding to a delay of 10-27 days in the time domain. If we take the mean value simply averaged over their table (Table 1 by Loyer et al. (1999)), we obtain 18.0 $\pm 7.2^{\circ}$ (21.8 days). Comparing with the phase lag expected from theoretical estimates based on the anelasticity of the earth (Dehant and Zschau, 1989; Wahr and Bergen, 1986), we conclude that the observed phase lag is too large to be the effect of mantle anelasticity. What, then, is the origin of this observed phase lag? This question is one of the motivations of this study.

There are several possible sources which may produce the phase lag, including atmospheric loading, water table changes and ocean dynamics. Among them,

\footnotetext{
${ }^{2}$ Home page, http://hpiers.obspm.fr/iers/eopc04/EOPC04.GUIDE.
}

we suspect the effect of sea surface height (SSH) variations may be a major contribution. As the first step in our study of the polar motion effect on gravity, we have evaluated the effect on the annual component at the actual SG observation sites. Since the annual component of the polar motion is a forced motion, we consider that the effect on the annual component will be much simpler and better determined than that of the Chandler component which is a rotational free motion of the earth, so we examine here mainly the relation between the observed and predicted annual gravity changes.

In the following sections, we begin by describing the SG data focussing on the annual gravity changes, and then we describe the SSH data used here and its gravity effects. Finally, we discuss a possibility to detect the SSH effect on gravity in other frequency bands.

\section{Observed annual gravity changes}

\subsection{Gravity data and processing}

The gravity data employed in this study were obtained from the SGs at three of the six sites of the GGP-Japan network which is a SG observation network being developed by Japanese SG group — from the north: three in Japan (Esashi, Matsushiro and Kyoto), Bandung in Indonesia, Canberra in Australia, and Syowa Station on east Ongul Island in Antarctica (Sato et al., 1999; quite recently, a seventh station was established at Ny-Alesund on Svalbard in Norway). The three sites used here are Esashi, Canberra and Syowa. The geographical coordinates of the sites are listed in Table 1 along with the data periods used in this study. Since the observation at Canberra began in January 1997, the available data length is short compared with other two sites. It is well established that changes in the height of the water table in soil or sedimentary layers affects the observed gravity (for example, Delcourt-Honorez, 1986; Mukai et al., 1999; van Dam and Francis, 1998). We chose these three sites in order to minimize the effect of the changes in water table on our comparison between observed and predicted annual variations. At these sites, the effect of the water table is expected to be small because the observation piers are set directly on massive basement 
Table 1

SG data used in this study

\begin{tabular}{llrrrl}
\hline Site & Latitude & Longitude & Altitude $(\mathrm{m})$ & Gravimeter & Analysis period \\
\hline Syowa Station & $69.006^{\circ} \mathrm{S}$ & $39.586^{\circ} \mathrm{E}$ & 24 & TT\# 016 & March 1993-December 1997 (1552 days) \\
Canberra & $35.321^{\circ} \mathrm{S}$ & $149.008^{\circ} \mathrm{E}$ & 724 & CT\# 031 & January 1997-April 1999 (776 days) \\
Esashi & $39.148^{\circ} \mathrm{N}$ & $141.335^{\circ} \mathrm{E}$ & 393 & TT\# 007 & January 1995-April 1999 (1337 days) \\
\hline
\end{tabular}

${ }^{\text {a }}$ TT and CT indicate the old type and the new compact type of SG, respectively.

rock and the soil layer at each site is very thin, which can preserve a water table. It is known that there is no sediment layer at Syowa (Ito et al., 1984).

The original signals collected through an analog low-pass filter of time constant $50 \mathrm{~s}$ are sampled every 1 or $2 \mathrm{~s}$ with an analog/digital converter of 7.5 digit accuracy. The least significant figure of the digital data corresponds to a gravity change of about $0.1 \mathrm{nGal}$ $(1 \mathrm{nGal}=0.001 \mu \mathrm{Gal})$. The scale factor $(\mu \mathrm{Gal} / \mathrm{V})$ of each gravimeter was calibrated by comparison with an absolute gravimeter (Aoyama et al., 1997; Sato et al., 1996). The magnitude of step-like changes (offsets) in the original data were estimated based on the daily medians computed from the $1 \mathrm{~min}$ data corrected for the theoretical tide and air pressure effects.

The corrected $1 \mathrm{~min}$ data was processed in two steps in order to pull out the long-period signals. First, a tidal analysis program called BAYTAP-G (Tamura et al., 1991) was applied to the $1 \mathrm{~h}$ data sampled from the corrected 1 min data in order to decompose the original data into four components, the short-period tidal component, the response to associated data, the trend and the irregular noises. The air pressure data obtained at each observation site was included as associated data in the analysis for each site. Next, the data resampled at a 1-day interval (at $00.00 \mathrm{~h}$ UTC) from the $1 \mathrm{~h}$ trend data was decomposed into three components, the long-period tide, the trend and the irregular noise, by means of BAYTAP-L. BAYTAP-L is another version of the BAYTAP programs which was developed to analyze the long-period tides. Although the tidal potentials used in this program are changed from those of short-period waves ( $1 / 3$ to 1 day) to those of long-period ones (4-5 to 31 days), the method of optimization and the decomposition scheme are essentially the same as those of BAYTAP-G. Thus, the obtained trend component contains time variation components having a period longer than the monthly tide.
In this paper, we adopt a sign convention for the gravity data such that an increase in strength of gravity (i.e. downward acceleration) corresponds to a positive increase of gravity, and all phases are referred to 1 January $2000,00.00 \mathrm{~h} \mathrm{UTC}$, as the epoch for the analysis.

\subsection{Polar motion effect}

The variations in EOP, either changes in the position of the rotation axis (polar motion) or spin rate of the earth (length of day, LOD) cause a perturbation of gravity through changes in the centrifugal force. At the level of accuracy treated in this study $(0.1 \mu \mathrm{Gal})$, the effects of LOD changes can be safely neglected because they are about two orders of magnitude smaller than that of the polar motion. With this approximation, the gravity change $\Delta g$ on the earth's surface due to the EOP changes may be written to first-order as

$\Delta g=\delta \Omega^{2} a \sin 2 \theta(x \cos \lambda-y \sin \lambda)$

(for example, Kaneko et al., 1974; Wahr, 1985). In the above equation $\delta=1+h-(3 / 2) k$ is the gravimetric factor containing the second-order Love numbers $h$ and $k . \Omega$ is the mean angular velocity of the earth, $a$ is the radius of the earth, and $\theta$ and $\lambda$ are the co-latitude and east longitude of the observation site, respectively. $x$ and $y$ are the time variations in the Celestial Ephemeris Pole relative to the International Reference Pole. Using Eq. (1) and assuming the $\delta$ factor to be 1.155 , a nominal value given by Wahr (1981), we can obtain a time series for $\Delta g$ from the daily EOP data. We use here the 'EOPC04' EOP data provided by IERS.

To safely separate the annual component from the Chandler component, we would need a data length of at least 6 years, but the available gravity data do 
not satisfy this condition. Therefore, we have used a method suggested by Richter (1990) in order to reduce the contamination of the annual components of the polar motion by the Chandler component. Thus, we first compute predicted gravity changes using a long time series of EOP data sufficient to separate the annual and Chandler component. Then, the time series data for the Chandler component was decomposed from the predicted gravity data by fitting a model which consists of the five terms; a constant term, a linear trend term and three periodic terms (semiannual, annual and Chandler components), by means of a least squares method.

Since the temporal stability of Chandler period directly affects the reliability of the results obtained by the fitting process mentioned above, we first examined its stability using 22 years of EOP data from January 1977 to December 1998. For this purpose, a time series $\Delta g$ for the Canberra site was generated. The amplitude there is the largest among the three observation sites (about $10 \mu \mathrm{Gal}$ in the maximum peak-to-peak amplitude). The temporal changes of the periodic terms were examined by fitting 6-year segments of the dataset and by successively shifting the analysis epoch by 1 year. The optimum Chandler period for each 6-year dataset was selected to minimize the root mean square error for the residuals. As noted in the home page of the IERS website, the accuracy of the observed EOPs was greatly improved after 1983 mainly due to the improvement in the space geodetic observation techniques. In the present analysis, we also confirmed that large changes in the Chandler period for analysis periods before 1983 are substantially reduced after 1983. Thus, our analysis suggests that the Chandler period is stable within the range 433.0-437.1 days over the 16-year period from 1983 to 1998 . Over the 16-year period the mean value averaged $435.4 \pm 1.3$ days.

\subsection{Determination of the parameters of annual gravity change}

The parameters of annual gravity change (i.e. the coefficients of the cosine and sine terms) were estimated by fitting the following analysis model to the observed daily trend data $y(t)$. The fitting was carrying out by a non-linear least squares method, the Levenberg-Marquardt method (Press et al., 1989). The analysis model used is

$$
\begin{aligned}
y(t)= & b_{0}+b_{1} t+b_{2} \exp \left(-\frac{t}{\tau}\right)+b_{3} \sin \left(\varpi_{1} t\right) \\
& +b_{4} \cos \left(\varpi_{1} t\right)+b_{5} \sin \left(\varpi_{2} t\right)+b_{6} \cos \left(\varpi_{2} t\right) \\
& +b_{7}\left(P(t)-b_{8} \Delta P(t)\right)+\sum_{k=1}^{n} c_{k} H\left(t-t_{k}\right)
\end{aligned}
$$

where $t$ is the observation time in days, $\varpi_{1}$ and $\varpi_{2}$ the angular frequencies of the annual and semiannual components, $\tau$ the time constant of the exponential drift, $P(t)$ the time series data mainly consisting of the gravity effect due to the Chandler component, $b_{7}$ the coefficient corresponding to the observed gravimetric factor for the Chandler component, $\Delta P(t)$ the first time difference of $P(t), b_{8}$ the coefficient of $\Delta P(t)$, which represents a time lag of the observed gravity $y(t)$ against $P(t)$, and $H_{n}(t)$ and $b_{n}$ are Heaviside's step function and its amplitude, respectively. $10+n$ unknown parameters are to be estimated: $b_{0}, b_{1}, b_{2}$, $b_{3}, b_{4}, b_{5}, b_{6}, b_{7}, b_{8}, \tau$ and $c_{1}$ to $c_{n}$. A similar analysis model but ignoring the last term has been used by Mukai et al. (1999) to analyze SG data obtained at Kyoto, Japan.

The time series $P(t)$ was obtained by the following procedures: (1) for each observation site, the time series $\Delta g$ was generated by setting the value of $\delta$ to 1.0 and using the EOP data which are long enough (16-year period from 1983 to 1998) to separate the three periodic terms (semiannual, annual and Chandler), (2) by assuming 435.4 days as the Chandler period, the mean amplitudes and phases of these three periodic terms were evaluated using the model described in this section, (3) finally, $P(t)$ was derived by subtracting the obtained four components, the constant, the linear trend, the semiannual and annual components, from $\Delta g$. Thus, we believe that the time series $P(t)$ consists mainly of the Chandler component. From the fitting used the model given in Eq. (2), the annual and semiannual components due to the EOP changes are obtained together with the effects of the tides, SSH variations and other seasonal perturbations. The Heaviside step function term was introduced to re-estimate the magnitude of any step-like changes (offsets) which may be included in the observational data, and which were not completely removed using the daily medians as described in Section 2.1. 


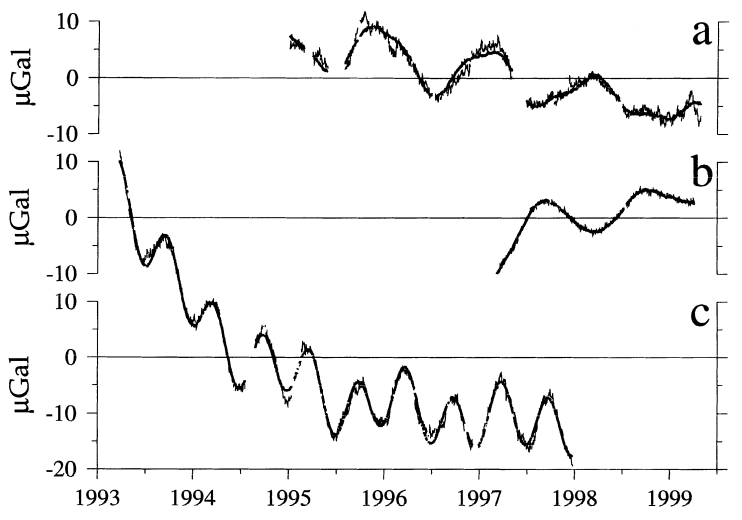

Fig. 1. The observed daily trends and the results for fitting. Eq. (2) shown in the text is used for fitting. Thin zig-zag lines show the observed daily trends and thick smooth lines show the fitted curves. From the top, parts 'a', 'b' and 'c' are the results for Esashi, Canberra and Syowa, respectively.

Fig. 1 shows a comparison of the observed trends with the model values for the three sites. From the top, the results for Esashi, Canberra and Syowa are plotted. Long interruptions are observed in the data for Esashi and Syowa. These are mainly due to instrument malfunctions for which periods the data were discarded. In general, a large step occurred at these points. This is the reason why we included the step correction term into the analysis. Although the observed data were affected by several disturbances, we recognize from Fig. 1 that, for any of the observation sites, the observed gravity changes are well represented by the analysis model given by Eq. (2). Table 2 gives the analysis results for the annual and Chandler components and their estimation errors. We will discuss results shown in Table 2 in Sections 4.3 and 4.4 related to the effects of the step correction and of the correlation among the parameters.

\section{Effect of SSH variations on gravity}

\subsection{SSH and SST data}

Two SSH data were compared. One is the 3.2-year series derived from the POCM (Semtner and Chervin, 1992; Stammer et al., 1996), which corresponds to the T/P repeat cycles 2-119 (17 October 1992 to 22 December 1995). The other is the SSH data obtained from the T/P altimeter for the same period. These two datasets were provided by Naval Post-Graduate School of USA (NPS). The SST data, which have been used to derive the POCM (Tokmakian, 1998, personal communication), were used to estimate the steric effect in the SSH variations (the thermal steric effect in our case). This SST data was also provided by NPS.

The POCM is a general circulation model for the ocean, which is derived by the forcing of wind-stress and heat-flux. The model is based on the primitive equations using the hydrostatic and Boussinesq approximations and covers the ocean regions from $65^{\circ} \mathrm{N}$ to $75^{\circ} \mathrm{S}$ in latitude. The data used here are from the recent POCM_4B version. Although the SSH data output from the model computation are given on a grid with a nominal lateral resolution of $1 / 4^{\circ}$ in both latitude and longitude, we averaged the original data over a $1^{\circ} \times 1^{\circ}$ grid.

On the other hand, the T/P data used here are 'filtered T/P data' on a $2^{\circ} \times 2^{\circ}$ grid, which were smoothed by applying the spatial low-pass filter proposed by Shapiro (1970) in order to reduce stationary small scale sea surface fluctuations mainly related to geoid errors. This data covers the ocean regions between 0 and $\pm 66^{\circ}$ latitude. In addition to the steric effect, the altimeter data are also affected by the sea surface pressure changes. The T/P data has therefore been cor-

Table 2

The observed annual and Chandler components obtained from the three SG sites ${ }^{\mathrm{a}}$

\begin{tabular}{|c|c|c|c|c|c|c|c|c|c|}
\hline \multirow[t]{2}{*}{ Site } & \multicolumn{4}{|l|}{ Annual component } & \multicolumn{4}{|c|}{ Chandler component } & \multirow[t]{2}{*}{ S.D. $(\mu \mathrm{Gal})$} \\
\hline & Amplitude $(\mu \mathrm{Gal})$ & Error $(\mu \mathrm{Gal})$ & Phase $\left(^{\circ}\right)$ & Error $\left(^{\circ}\right)$ & Factor & Error & Delay (days) & Error (days) & \\
\hline Esashi & 1.30 & \pm 0.11 & -2.1 & \pm 6.5 & 1.17 & \pm 0.04 & -9 & \pm 2 & 1.09 \\
\hline Canberra & 1.88 & \pm 0.09 & -147.8 & \pm 7.0 & 1.09 & \pm 0.09 & 4 & \pm 2 & 0.32 \\
\hline Syowa & 0.77 & \pm 0.08 & 31.2 & \pm 5.6 & 0.86 & \pm 0.06 & -10 & \pm 3 & 0.91 \\
\hline
\end{tabular}

${ }^{a}$ Error shows the formal $1 \sigma$ error inferred from the standard deviation (S.D.) of residuals after fitting. Phase is that referred to an epoch of 00.00 h UTC, 1 January 2000. 
rected for the pressure effect using the inverse barometer (IB) hypothesis (Stammer, 1997).

\subsection{Steric coefficient}

The POCM estimates the variations in bottom pressure in the ocean. In general, the relation between the bottom pressure $P_{\mathrm{b}}$ and the sea surface height variations $\zeta$ is represented by $\zeta=P_{\mathrm{b}} / g \rho_{0}=\zeta^{\prime}-\zeta_{\rho}+\zeta_{\mathrm{a}}$, where $g$ is the surface gravity, $\rho_{0}$ the mean surface water density, $\zeta^{\prime}$ the height change related to pressure, $\zeta_{\rho}$ being the steric height, and $\zeta_{\mathrm{a}}$ is the height corresponding to the averaged pressure over the global ocean (Ponte, 1999). The POCM output includes both the signals in $\zeta^{\prime}$ and $\zeta_{\rho}$ (Ponte, 1999). However, the steric variation $\zeta_{\mathrm{a}}$ does not cause any significant gravity changes and it must be removed in our gravity analysis. Thus, we applied a steric correction to the POCM data, as well as the T/P data. We considered here the only thermal steric effect. The thermal steric coefficient $\alpha_{i, j}$ was estimated by fitting following equation to each grid by means of the least squares method:

$\Delta \operatorname{SSH}\left(\theta_{i}, \lambda_{j}, t\right)=\alpha_{i, j} \Delta \operatorname{SST}\left(\theta_{i}, \lambda_{j}, t\right)$

where $\theta_{i}$ and $\lambda_{i}$ are the co-latitude and longitude of each ocean grid, $t$ the time of each data point, and $\Delta \operatorname{SSH}\left(\theta_{i}, \lambda_{j}, t\right)$ and $\Delta \operatorname{SST}\left(\theta_{i}, \lambda_{j}, t\right)$ are the deviatoric parts of SSH and SST on each grid, obtained by subtracting their mean values.

From the fit based on the POCM SSH data, we have obtained values of $\alpha_{i, j}$ within the range from $-1.30 \times 10^{-2}$ to $1.58 \times 10^{-2} \mathrm{~m} /{ }^{\circ} \mathrm{C}$. Since the main feature of the spatial variations of the SST data is a zonal one, we examined the characteristics of the spatial distribution of the obtained $\alpha_{i, j}$ values by averaging them zonally over $10^{\circ}$ wide belts across the ocean basin each of the Pacific, Atlantic and Indian Oceans. The averaged values vary between $-0.06 \times$ $10^{-2}$ and $1.09 \times 10^{-2} \mathrm{~m} /{ }^{\circ} \mathrm{C}$, and the main characteristics in their spatial distribution are (1) high latitude regions in both the northern and southern hemispheres show low values $\left(0.2 \times 10^{-2}\right.$ to $\left.0.3 \times 10^{-2} \mathrm{~m} /{ }^{\circ} \mathrm{C}\right)$, (2) in low latitude regions within $\pm 20^{\circ}, \alpha_{i, j}$ shows complex spatial distribution and the averaged values range within $-0.06 \times 10^{-2}$ to $1.09 \times 10^{-2} \mathrm{~m} /{ }^{\circ} \mathrm{C}$, (3) in mid-latitudes of Pacific Ocean, the southern hemisphere region shows relatively low values compared with those for the northern hemisphere, however, this tendency is not so clear in the Atlantic Ocean, and (4) ocean regions where strong western boundary currents such as Kuroshio or the Gulf Stream flow showed a complex spatial distribution of $\alpha_{i, j}$, but its variation is smaller than that in the low latitudes and $\alpha_{i, j}$ is distributed around a value of $0.60 \times 10^{-2} \mathrm{~m} /{ }^{\circ} \mathrm{C}$.

The regression coefficient $\alpha_{i, j}$ clearly varies with the location, but as an approximation, we have evaluated an average coefficient over the central regions of the Pacific and Atlantic Oceans. We chose these regions for the following reasons: (1) a reliable mean steric coefficient could be evaluated from the ocean regions where a high correlation between SST and SSH is observed, and (2) we avoid possible disturbance due to the effect of strong ocean currents. Consequently, we obtained a value of $0.60 \times 10^{-2} \mathrm{~m} /{ }^{\circ} \mathrm{C}$ from the POCM SSH data, and $0.52 \times 10^{-2} \mathrm{~m} /{ }^{\circ} \mathrm{C}$ from the $\mathrm{T} / \mathrm{P}$ data. In what follows we adopt a value $0.60 \times 10^{-2} \mathrm{~m} /{ }^{\circ} \mathrm{C}$ to correct for the steric effect in both the POCM and T/P SSH data.

\subsection{EOF of the SSH data}

Prior to the estimation of the gravity effect of annual SSH variations, we evaluated the empirical orthogonal functions (EOFs) of both the SSH and SST data by applying the principal component analysis (PCA; Preisendorfer and Mobely, 1988) in order to examine the efficiency of our steric correction.

First, we evaluated the EOFs of the SST data and those of the original POCM SSH data which were not corrected for the steric effect. As is to be expected, the dominant signal in both the SST and SSH is the annual one, and this signal appears clearly and commonly in the first modes which show a symmetrical spatial variation about the equator.

Next, based on the SSH data corrected for the steric effect, we re-evaluated the EOFs. Fig. 2 shows the EOFs computed using the corrected POCM SSH data. From the top, the three principal components of the first, second and third modes are displayed. Among the features observed in the corrected EOFs, the notable points are (1) in the first mode (Fig. 2a), the strong symmetrical spatial pattern about the equator is clearly moderated especially in the Pacific and Atlantic Oceans, (2) in the second mode (Fig. 2b), a symmetrical oscillation about the equator which is 

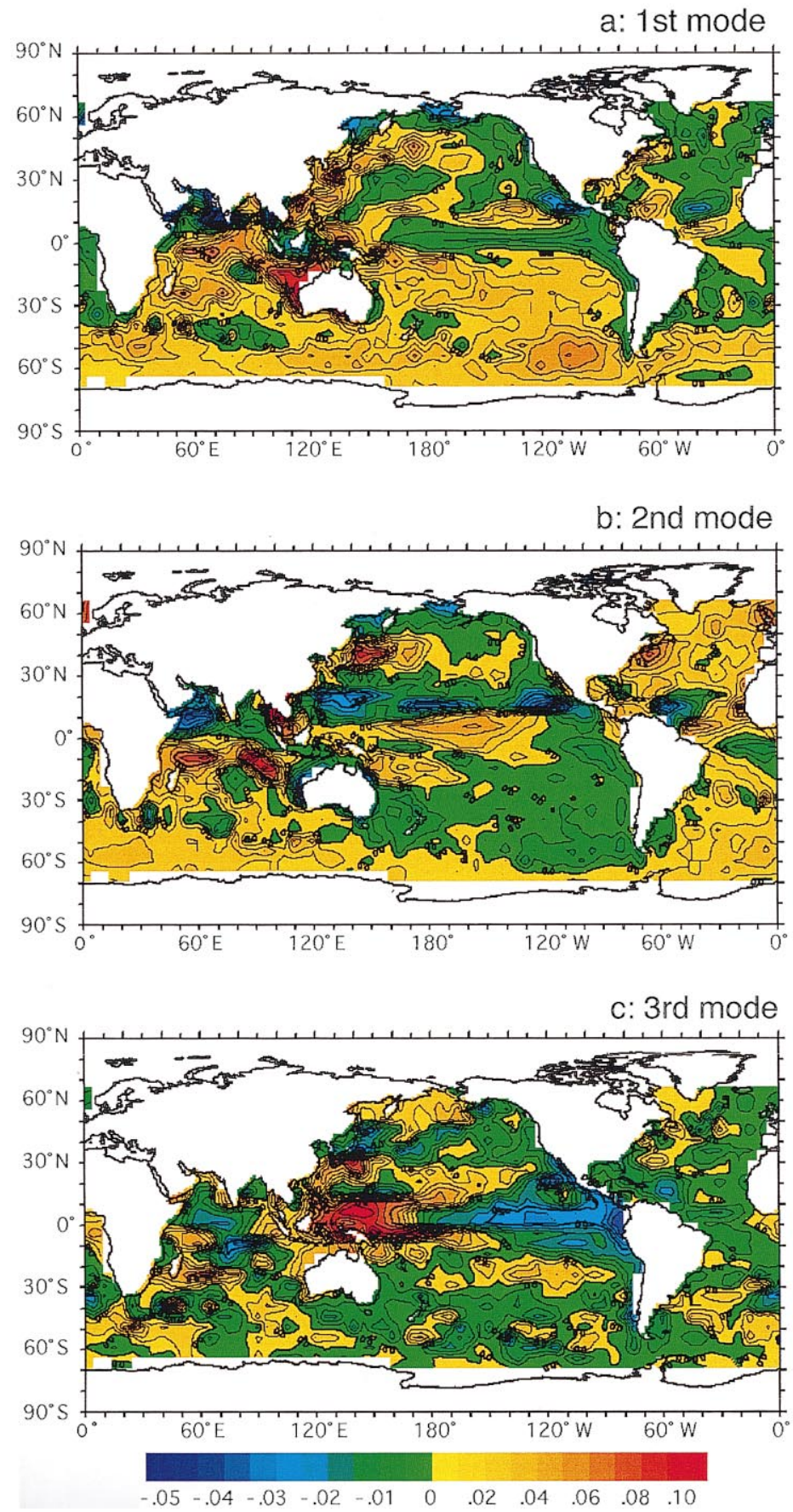

Fig. 2. Empirical orthogonal functions (EOFs) evaluated from the POCM SSH data. The steric effect was corrected for this data using the coefficient of $0.60 \times 10^{-2} \mathrm{~m} /{ }^{\circ} \mathrm{C}$. From the top, the first mode (a), second mode (b) and third mode (c) are displayed. 
localized in tropical regions is observed, and (3) in the third mode (Fig. 2c), an El Nino southern oscillation (ENSO)-like oscillation clearly appears. For the temporal variations, the 1-year periodic signal is still a dominant signal in both the first and second modes. However, the annual signal is not dominant in the third mode using the corrected SSH data. Instead the 1-year period, a long-term trend, which has a peak at around the mid of May 1994, is observed in the third mode.

From the feature of the EOFs corrected for the steric effect, we infer that our steric correction works well.

\subsection{Calculation of the gravity effect of the annual SSH variations}

Although the seasonal changes are the dominant component in both the SSH and SST data, these data did not show a simple annual sinusoidal variation in time. Instead, they usually include an overtone of the annual period. Therefore, we evaluated the annual fields of the SSH and SST by applying an analysis model which consists of the constant, linear, annual and semiannual terms, to each ocean grid. By considering the semiannual component in the analysis, we expect to reduce the estimation error of the annual component.

The gravity change due to the effect of SSH variations (i.e. the effect of attraction and loading) can be evaluated by convolving SSH data with a gravity Green's function over the whole ocean area. This computation has been carried out using a modified version of the computer program 'GOTIC' which was developed to compute the effects of ocean tides (Sato and Hanada, 1984). In order to improve the accuracy of the global digital topographic maps, the original maps used in GOTIC were replaced with the 5 min $\times 5$ min 'ETOPO5' digital map (National Geophysical Data Center, 1988). The Green's function for the Gutemberg-Bullen earth model given by Farrell (1972) was used for the convolution integral. Farrell (1973) introduced a disk factor into the convolution process in order to take into account of the effect of a finite area of ocean mesh enclosing the observation site. Instead of this method, GOTIC carries out the convolution for the ocean meshes within $30^{\circ}$ of the load by applying the analytical integration formula derived by approximating the Green's function with a second order polynomial (Sato and Hanada, 1984).
Agnew (1983) pointed out that unconserved mass in the ocean tide model gives a systematic error in the results for convolution integral that cannot be ignored. In the case of ocean circulation models, models usually make the Boussinesq approximation and conserve volume, rather than mass (Greatbatch, 1994). For the POCM, the computation is done in a similar manner (Tokmakian, 1998, personal communication). Therefore, the volume adjustment may not have to be done again. But, since the estimated steric field does not conserve its volume, we applied the correction for unconserved volume to the POCM data, as well as the T/P data. Thus, we estimated an ocean height which is obtained by averaging the SSH at each time over the whole ocean grids, and subtracted it uniformly from the SSH of each grid. Here, a value of $1.025 \times 10^{-3} \mathrm{~kg} / \mathrm{m}^{3}$ was adopted for sea water density throughout the whole ocean.

\section{Results and discussions}

\subsection{Annual SSH variations}

Fig. 3 shows the spatial distribution of the annual amplitude and annual phase evaluated from the POCM SSH data. Three kinds of amplitude and phase fields are displayed. From the top, they are for the original SSH (Fig. 3a and b), the steric component (Fig. 3c and d) and the SSH corrected for the steric effect (Fig. 3e and f), respectively.

Comparing Fig. 3a with Fig. 3e, it is clear that the large high amplitude zone in the central parts of both the Pacific and Atlantic Oceans in the northern hemisphere (i.e. the area roughly spanning $20-50^{\circ} \mathrm{N}$ and $150-195^{\circ} \mathrm{E}$ ) is significantly reduced by correcting for the steric effect. We also observe a similar tendency in the southern hemisphere mid-latitude regions in both the Pacific and Atlantic Oceans, although the degree of change is small compared with the northern hemisphere. In contrast to this, amplitude changes from the steric correction are not clear in either the Indian Ocean or low latitude regions of the Pacific and Atlantic Oceans. Fig. 2c and e also indicate that the SST may be not the dominant source of the annual SSH change there. Moreover, from the comparison between the uncorrected SSH amplitude (Fig. 3a) and the corrected one (Fig. 3e), it is apparent that the 

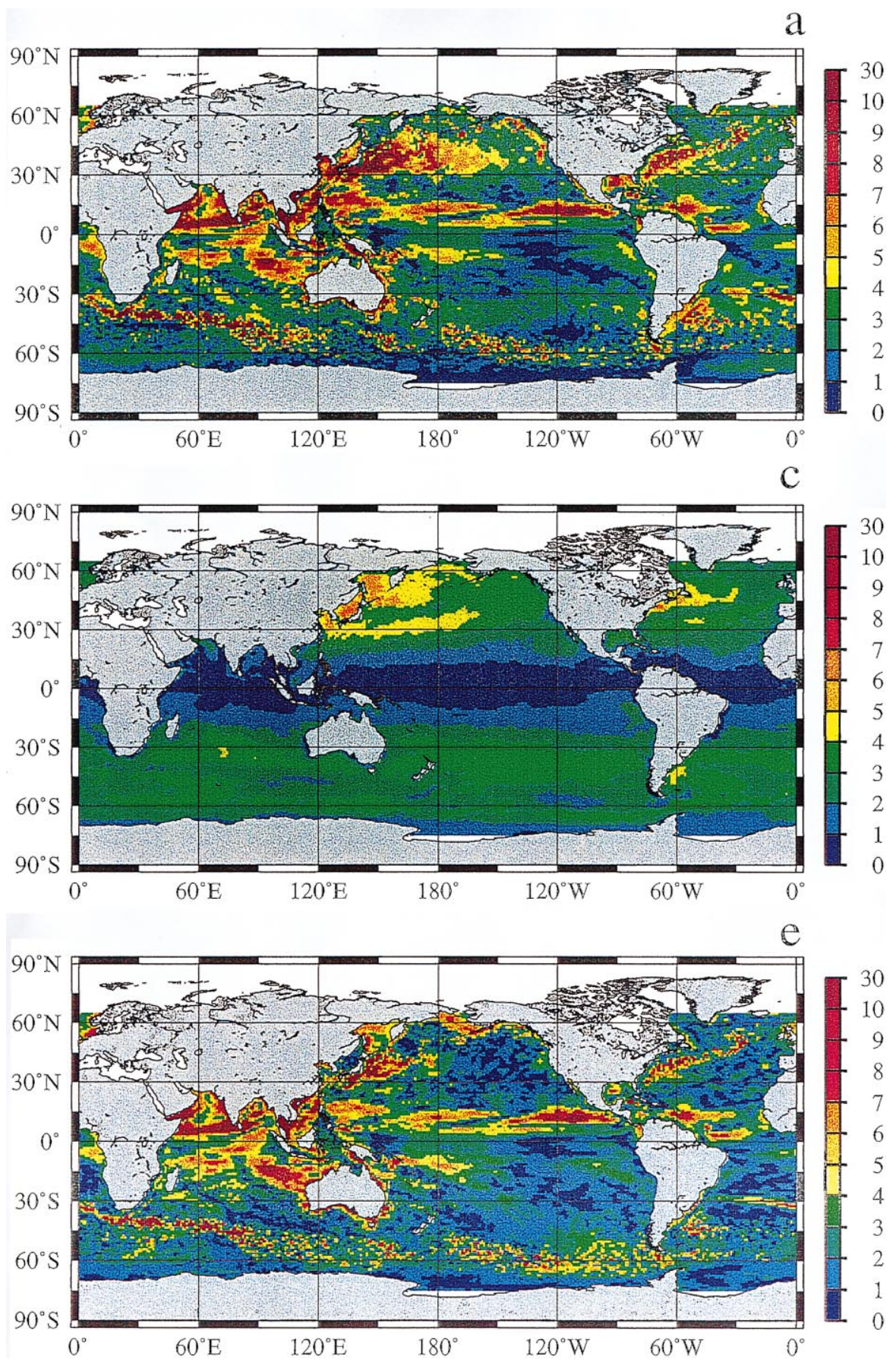

Fig. 3. Amplitude and phase of the annual SSH fields evaluated from the POCM SSH and SST data. From the top, three fields are displayed: the original field; the steric field; the field corrected for the steric effect. The coefficient of $0.60 \times 10^{-2} \mathrm{~m} /{ }^{\circ} \mathrm{C}$ was used for the correction. The amplitude fields are shown in parts 'a', 'c' and 'e' in the order of the original, steric and corrected fields, respectively. The phase fields are shown in parts ' $\mathrm{b}$ ', ' $\mathrm{d}$ ' and ' $\mathrm{f}$ ' in the same order. The units of color bars are in $1 \times 10^{-2} \mathrm{~m}$ for the amplitude and in degrees of arc for the phase. 

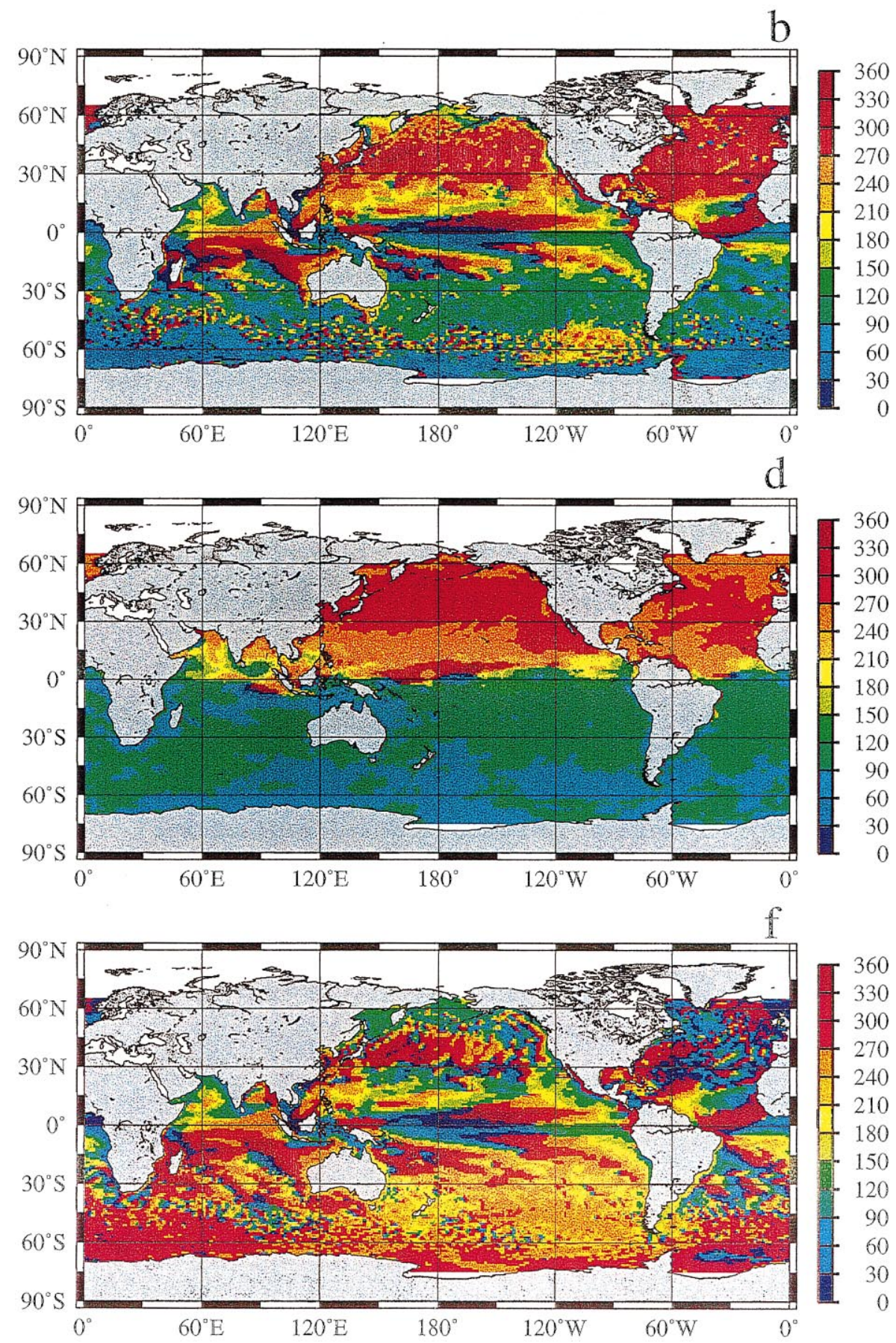

Fig. 3. (Continued). 
large extent of high amplitude regions accompanying the two western boundary currents (i.e. Kuroshio and Gulf Stream) is substantially reduced by correcting for the steric effect. However, the steric correction is not so effective in the circumpolar current. We also observe an effect of over-correction in the northern high latitude regions, for example, in the northern part of Bering sea or that of Sea of Okhotsk. We adopted the value of $0.60 \times 10^{-2} \mathrm{~m} /{ }^{\circ} \mathrm{C}$ as the steric coefficient, but the mean value obtained in these regions is small as about $0.25 \times 10^{-2} \mathrm{~m} /{ }^{\circ} \mathrm{C}$, and the mean amplitude of annual SST changes in that latitude zone is not so small. These factors may affect the overcorrection.

Stammer (1997) presents images similar to Fig. 3, which have been obtained from 3 years of T/P data from repeat cycles 7 through 116 (see Plate 6 of his paper). The steric field he shows, which was computed by integrating the sea surface heat fluxes in time, is more rigorous than that obtained here from only the simple temporal correlation between the SSH and SST fields. However, the two SSH fields corrected for the steric effect show very similar spatial variations in amplitude. This may be important for practical application to gravity observations when only the SST data are available for the steric correction.

Doi (1993) estimated the thermal steric coefficient based on the T/P SSH data and the SST data obtained from Geostationary Meteorological Satellite of Japan (GMS), and he obtained the values within the range between $1.28 \times 10^{-2}$ and $4.43 \times 10^{-2} \mathrm{~m} /{ }^{\circ} \mathrm{C}$. His values are about three to seven times larger than those obtained here. Recently, Leuliette and Wahr (1999) have investigated the time-space coherence between the T/P SSH fields and the SST fields prepared by National Centers for Environmental Prediction of USA (NCEP) by means of a modified EOF analysis called 'coupled mode analysis' (Bretherton et al., 1992). Their results also suggest that the Indian Ocean basin has a distinctly different character in the correlation between SSH and SST compared with that in the Pacific and Atlantic basins (see their Fig. 4 and Table 2). They obtained $0.79 \times 10^{-2}$ and $0.94 \times 10^{-2} \mathrm{~m} /{ }^{\circ} \mathrm{C}$ as the correlation coefficients of the first mode for Pacific and Atlantic, respectively (see their Table 2). These values are about $40 \%$ larger than the mean coefficient obtained here from the POCM data $\left(0.60 \times 10^{-2} \mathrm{~m} /{ }^{\circ} \mathrm{C}\right)$ or the T/P data $\left(0.52 \times 10^{-2} \mathrm{~m} /{ }^{\circ} \mathrm{C}\right)$.

\subsection{Annual gravity changes}

Fig. 4 shows the variability of the annual gravity changes on land, which was estimated from the POCM $\mathrm{SSH}$ data corrected for the steric effect using a coefficient of $0.60 \times 10^{-2} \mathrm{~m} /{ }^{\circ} \mathrm{C}$. The data are averaged on a $5^{\circ} \times 5^{\circ}$ grid system. This plate indicates that most of the high amplitude areas (i.e. at where the variance is larger than $1.5 \mu \mathrm{Gal}$ ) are removed by correcting for the steric effect. From Fig. 4, it is concluded that the gravity effect induced by the annual $\mathrm{SSH}$ changes is less than $0.5 \mu \mathrm{Gal}$ in amplitude at most inland sites in the world, except for coastal or island observation sites.

Figs. 5 and 6 show the comparison between the observed and predicted annual components at the three observation sites, Esashi, Canberra and Syowa, respectively. The horizontal and vertical axes correspond to the cosine-term and sine term, respectively. Thus, the amplitude is represented by the length of vector and the phase angle as its angle measured from the cosine axis, counter clockwise for a lag. The phases of all vectors are referred to the epoch at $00.00 \mathrm{~h} \mathrm{UTC}$ on 1 January 2000. Four effects, the solid tide, the ocean tide, the polar motion and the SSH, were combined here to estimate the predicted vectors. The SSH vectors evaluated from the POCM data and the T/P data are displayed in Figs. 5 and 6, respectively. In Fig. 6, we extrapolated SSH variations for a few degrees into the Syowa area from nearby oceans by means of a spline method, because the Syowa site is located at $69^{\circ} \mathrm{S}$ latitude, beyond the $\pm 66^{\circ}$ limit of the T/P data. The solid tide vectors for the Sa wave were evaluated using Tamura's tidal potential (Tamura, 1987) assuming values of 1.155 and $0.0^{\circ}$ as nominal values of the gravity tidal factor and phase lag for the long-period tides. The ocean tide vectors were evaluated from the global ocean tide model for the Sa wave which was computed by Takanezawa (1998). The vectors of the annual polar motion effect were evaluated with the method described in Section 2.2 using the IERS EOP data for the 16-year period from 1983 to 1998.

The effects of both the solid and ocean tides on the Sa wave are very small at Esashi and Canberra located in mid-latitudes, but the effect of the solid tide is not so small at Syowa. The amplitudes at Esashi, Canberra and Syowa are 0.109, 0.000 and $0.926 \mu \mathrm{Gal}$ for the solid tide and $0.002,0.003$ and $0.070 \mu \mathrm{Gal}$ 


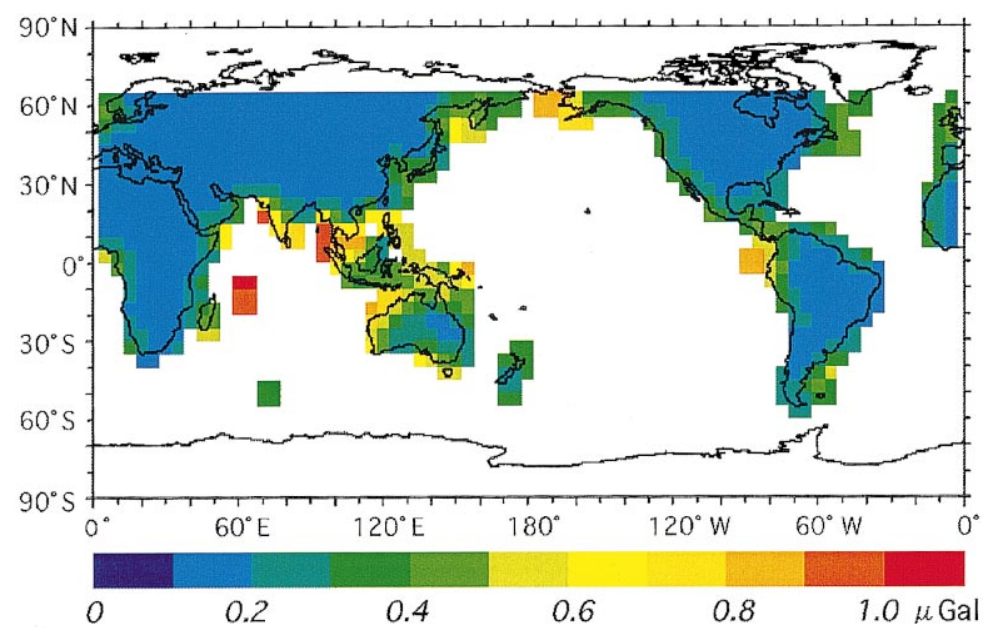

Fig. 4. Variability of the annual gravity changes induced by the SSH variations. This variability was computed based on the POCM SSH data which were corrected for the steric effect using the coefficient of $0.60 \times 10^{-2} \mathrm{~m} /{ }^{\circ} \mathrm{C}$.

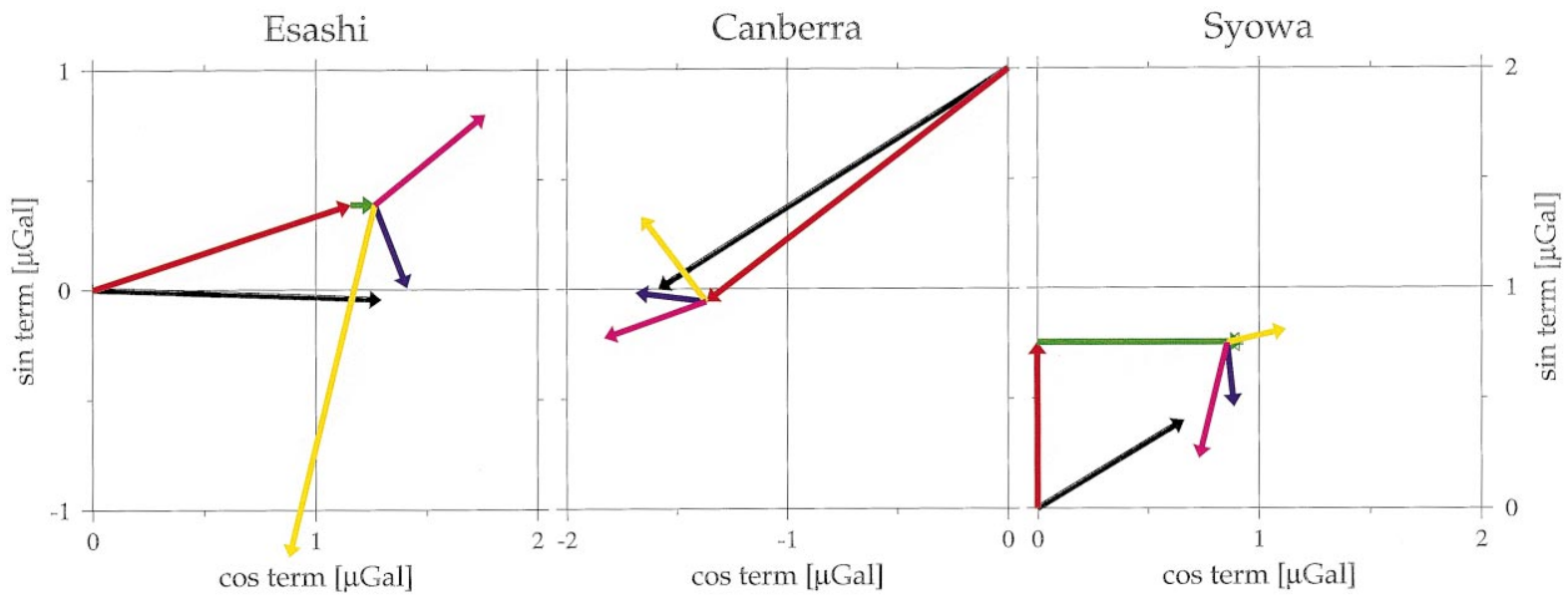

Fig. 5. Phasor plots of the observed annual components and predicted ones. The horizontal and vertical axes correspond to the cosine and sine terms, respectively. The phase angle of each vector is referred to an analysis epoch of $00.00 \mathrm{~h} \mathrm{UTC,} 1$ January 2000, and the angle is measured from the cosine axis, counter clockwise for a lag. From the left, the results for Esashi, Canberra and Syowa are displayed, respectively. The three vectors of black, red and green show the observation, the polar motion effect and the effect of solid tide, respectively. The effects of the Sa ocean wave are very small to display with the scale of this plot. Its effect is only displayed in the plot for Syowa as the small vector picked with white seeing at the top of the solid tide vector. The three vectors of yellow, blue and pink show the effect of SSH variations evaluated using the steric coefficients of $0.0 \times 10^{-2}, 0.60 \times 10^{-2}$ and $1.0 \times 10^{-2} \mathrm{~m} /{ }^{\circ} \mathrm{C}$, respectively.

for the ocean tide, respectively. In contrast to this, the magnitude of the annual polar motion effect is up to $1.73 \mu \mathrm{Gal}$ at Canberra. We ignored the annual air pressure effect in our prediction, because we expect that most of the long-period air pressure effect (more than 85-90\%) was excluded from the observed gravity trend obtained by the tidal analysis procedure using BAYTAP-G described in Section 2.1, except for the case of large and rapid pressure changes. The bases of this are the studies by Sato et al. (1990) and Mukai et al. (1995). At the annual period, it is also expected that the ocean response to the atmospheric pressure 


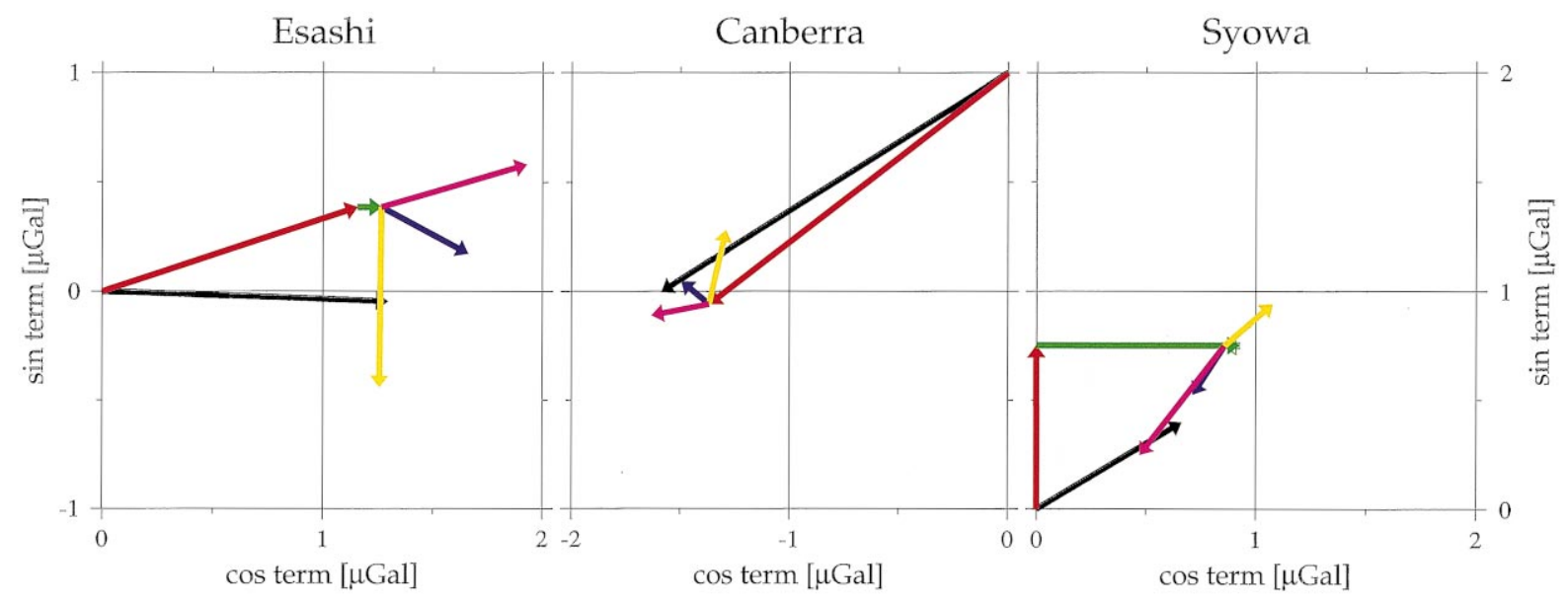

Fig. 6. Similar plots as in Fig. 5, but the SSH vectors evaluated from the T/P data are displayed.

changes is well approximated with an inverted barometer response, which has no loading effect on the gravity in an ideal case.

Figs. 5 and 6 suggest that the SSH variations cannot be ignored if gravity observations are made at an accuracy of better than $1 \mu \mathrm{Gal}$. Three SSH vectors are illustrated in each figure. These three are distinguished by the magnitude of the steric coefficients used for the correction. The three coefficients of $0.0 \times 10^{-2}$, $0.60 \times 10^{-2}$ and $1.0 \times 10^{-2} \mathrm{~m} /{ }^{\circ} \mathrm{C}$ were tested. The first case corresponds to no steric effect (the yellow vectors), the second is the preferred value estimated from the POCM SSH and SST data (the blue vectors), and the last is a test value for comparison (the pink vectors). As shown in Fig. 5 and 6, an important point for the SSH effect is that its estimation is strongly affected by the magnitude of the steric coefficient used in the computation.

For the case using the POCM data (Fig. 5), among the three sites, the $\mathrm{SSH}$ vectors of Esashi have the largest amplitude and show a large difference in both the amplitude and phase with different values of the steric coefficient. The amplitude of SSH variations is large around Japan (see Fig. 3a and e) and the distance from the sea at Esashi relatively small (about $40 \mathrm{~km}$ ). These factors may contribute to the large amplitude there. Adding to this is the complex spatial distribution of annual phase in the ocean region around Japan mainly caused by strong ocean currents such as Kuroshio (see Fig. 3b and f). This may also contribute to the difference among the estimated SSH vectors because, due to the nature of both the Green's functions for the attraction and loading, the gravity effect from each ocean mesh is not simply proportional to its loading distance. The observation at Canberra at mid-latitude also indicates similar results as those for Esashi. For Syowa, it is more difficult to judge which steric coefficient of $0.60 \times 10^{-2}$ or $1.0 \times 10^{-2} \mathrm{~m} /{ }^{\circ} \mathrm{C}$ is favored by the observation. However, at least we can say that the SSH vector estimated by ignoring the steric effect shows the largest discrepancy in the phase.

It is noted that the results shown in Fig. 6 evaluated from the T/P data indicate a very similar dependence on the magnitude of the steric coefficients as that shown in Fig. 5. At Esashi, for example, both the amplitude and phase of the $\mathrm{SSH}$ vector obtained using $0.60 \times 10^{-2} \mathrm{~m} /{ }^{\circ} \mathrm{C}$ are intermediate in magnitude between those obtained using $0.0 \times 10^{-2}$ and $1.0 \times 10^{-2} \mathrm{~m} /{ }^{\circ} \mathrm{C}$. However, compared with the vectors estimated from the POCM data, the amplitudes estimated from the T/P data are systematically smaller by about $10-40 \%$ and the phases also show a systematic difference of about $20^{\circ}$ in the sense of advance. Canberra at mid-latitude also shows a similar tendency as seen in Esashi.

Although there exist some systematic differences between the estimations from the POCM and those from the $\mathrm{T} / \mathrm{P}$, the agreement between the observation and prediction is excellent for the mid-latitude sites. Figs. 5 and 6 indicate that we can reproduce the 
observed annual gravity changes at an accuracy of the order of $0.1 \mu \mathrm{Gal}$. It is worth noting that the observations favor a steric coefficient of $0.60 \times 10^{-2} \mathrm{~m} /{ }^{\circ} \mathrm{C}$. This means that the gravity observations made in the mid-latitudes support the steric coefficient which was independently estimated from the SSH and SST data in the mid-latitude ocean regions.

\subsection{Effect of offsets on the observed data}

Although the Canberra dataset is short, the errors in the amplitude and phase of the long-period component at this site are not greatly different from other analysis results using much longer data (see Table 2). Moreover, the standard deviation (S.D.) at the Canberra site is smallest among the three sites compared here. From the point of view of the analysis for the long-period components, the following three effects are believed to contribute to the above difference in the observation errors: (1) temperature change in the observation room at Canberra is low, (2) very few local earthquakes occur in the vicinity and (3) a Compact Tidal SG used in Canberra has been much improved compared with the old ones used other two sites (Warburton and Brinton, 1995). We consider that the effects (2) and (3) contribute most to the difference in the analysis errors shown above. It is evident from experience that the Canberra SG will have a smaller number of offsets from instrumental instabilities than the old SGs. Equally evident is that the Esashi SG located in an active subduction zone is more disturbed by large local earthquakes and the Syowa SG is more disturbed by increased artificial noise mainly caused by the operation ( 2 weeks) of the Helium liquefier in the observation room twice a year.

Based on a study for the correction for offsets by Sato et al. (1997), we have introduced here a Heaviside step function into the analysis model. For example, in the analysis of the Esashi data, we have re-estimated the four offsets with a total magnitude exceeding $100 \mu \mathrm{Gal}$ using this method. Compared with the data corrected for offsets using daily medians, the S.D. is improved using the step function in the fit by about $15 \%$ (i.e. from \pm 1.32 to $\pm 1.09 \mu \mathrm{Gal}$ ). Accompanying the reduction of the S.D., the estimation accuracy of the parameters is revised. However, our results suggest that the estimated time delay of the Chandler component (i.e. $b_{8}$ in Eq. (1)) is sensitive to the accuracy of the step correction. It is necessary to use the datasets longer than those used here in order to reduce the effect of the ambiguity in estimation of steps on the analysis results and to obtain more reliable parameters for the Chandler component.

Introducing a step function works well to reduce the estimation error, especially to improve the effect of offsets accompanying long interruptions. Of course the ideal way to maintain the sensitivity and calibration of the gravity record is by carrying out regular comparison observations with an absolute gravimeter at an accuracy of $1 \mu \mathrm{Gal}$ or better. In order to increase a reliability of the analysis for the annual and Chandler components, it is desirable to carry out such comparison observations twice a year at least.

\subsection{Error in the observed annual component}

The formal errors listed in Table 2 are the $1 \sigma$ errors estimated from the S.D. of the residuals. However, the magnitude of the errors, which were derived from a linearized least squares fit, may be somewhat optimistic from the point of view of the correlation among the unknown parameters. On the other hand, Figs. 5 and 6 suggest that the observed annual vectors favor the SSH vectors computed using a steric coefficient of $0.60 \times 10^{-2} \mathrm{~m} /{ }^{\circ} \mathrm{C}$. In order to verify this statement, we examined the confidence interval based on Monte Carlo simulation.

Since the effect of SSH variations at the Esashi site is largest among the three sites, we describe here the results for Esashi. As a test, we generated 1000 hypothetical datasets by adding Gaussian random errors to each data point of a model time series which was computed using the optimum parameter values and Eq. (2). The variance of the added noise is the same as that observed at Esashi and the data length of each hypothetical dataset is the same as that of the observed data. However, in the simulation we did not include the step-like changes (offsets) sometimes seen in the actual data. The correlation matrix obtained from the Esashi data indicates that the annual component shows a relatively high correlation (i.e. 30-50\%) with the Chandler component and some of the offsets. Moreover, the correlation between the cosine-term and the amplitude factor of the Chandler component (i.e. $b_{3}$ and $b_{7}$ in Eq. (2)) is higher than that with the time delay (i.e. $b_{8}$ ). We therefore estimated the confidence 
interval of the annual amplitude from the distribution in the two-dimensional parameter space $b_{3}-b_{7}$. For the same reason, the confidence interval of the phase was estimated from the distribution in $b_{4}-b_{8}$ space (i.e. the sine term of annual component and the time lag of Chandler component).

The simulation suggests that, at the $90 \%$ confidence level, the confidence intervals of $b_{3}$ and $b_{4}$ are at \pm 0.21 and $\pm 0.14 \mu \mathrm{Gal}$, respectively. Using these values, we obtain a range of $1.09-1.52 \mu \mathrm{Gal}$ and -9.7 to $4.9^{\circ}$ for the observed amplitude $(1.30 \mu \mathrm{Gal})$ and phase $\left(-2.1^{\circ}\right)$, respectively. Comparing these confidence intervals with the difference between the observed vector and the three predicted vectors shown in Fig. 5 and 6 , we see that, even with the correlation of the parameters taken into account, our observation still favors the $\mathrm{SSH}$ vectors estimated from the steric coefficient of around $0.60 \times 10^{-2} \mathrm{~m} /{ }^{\circ} \mathrm{C}$ rather than other two values.

\subsection{Possible error sources affecting the estimated annual SSH vectors}

\subsubsection{Grid size}

There is a possibility that the difference in grid sizes may contribute to the difference between the SSH vectors evaluated from respective $\mathrm{SSH}$ datasets. The spatial resolution of the $\mathrm{SSH}$ data used here are $1^{\circ} \times 1^{\circ}$ and $2^{\circ} \times 2^{\circ}$ for the POCM data and the T/P data, respectively. In general, the ocean region up to $30-40^{\circ}$ distant has the dominant effect on a gravity observation at a site near the ocean. For example, in the case of Esashi, a contribution of more than $80 \%$ of the gravity effect of the M2 ocean tide is due to the effect from the ocean region less than $20^{\circ}$ distant (Sato and Hanada, 1984), and the site is located at a place where the SSH variability is very high and the SSH field shows a complex spatial pattern (see Fig. 3). Therefore, an SSH field with a spatial resolution of $1^{\circ} \times 1^{\circ}$ or better may be necessary to represent the gravity changes accompanying the fine spatial variations in $\mathrm{SSH}$ to an accuracy better than $0.1 \mu \mathrm{Gal}$, especially for observation sites near the seas.

\subsubsection{Effect of the regional and global hydrologic cycles}

As seen in Figs. 5 and 6, there exist systematic differences in both the amplitude and phase of the annual
$\mathrm{SSH}$ vectors which were evaluated from the POCM and T/P data. A difference between the two datasets is that the T/P data include the effect of the global hydrologic cycle on the earth's surface but the POCM data do not. Changes in the ocean mass due to the hydrologic cycle (e.g. evaporation/precipitation and the land run-off of the fresh water to the oceans, which is usually not considered into the ocean modeling), may be a candidate to produce the above systematic difference, because these changes should have a major power at a period of 1 year. Johnson et al. (1999), who estimated the ocean angular momentum variability using the POCM data, suggest this problem in the POCM data. Ponte and Stammer (1999), who studied the excitation of polar motion based on a near-global ocean model, also pointed out the effect of hydrologic cycle as a possible error source making the discrepancy between the observed excitation functions and the estimated ones.

Our computation suggests that the results of the convolution integral are sensitive to the magnitude of the steric coefficient. For Syowa Station, the SSH vectors evaluated using $0.60 \times 10^{-2} \mathrm{~m} /{ }^{\circ} \mathrm{C}$ are not altogether good in comparison with the observation. This may suggest that the value determined for the seas in mid-latitudes is not a suitable coefficient for the sea around Syowa. The sea ice around Ongul Islands grows up to $3 \mathrm{~m}$ thick and its thickness changes seasonally. This may change the value of the effective steric coefficient there. Related to the hydrologic cycle, the depth of the snow layer on the ground in Ongul Islands also changes seasonally, but the attraction and loading effects of this was not taken into account in the present computation.

\subsubsection{Total mass of the oceans}

Treatment of the total mass of the oceans is important because (a) it can also make such systematic differences in the estimated amplitude and phase of the SSH vectors as shown in Figs. 5 and 6, and (b) the correction for the ocean mass conservation is not small in magnitude compared with the estimated annual gravity effect. For example, an error of $1 \times 10^{-3} \mathrm{~m}$ in the estimation of the thickness of the unconserved mass, which is to be subtracted from the SSH data, leads to an error of $0.052,0.045$ and $0.045 \mu \mathrm{Gal}$ in the estimated SSH vectors for Esashi, Canberra and Syowa, respectively. For a mid-continent comparison, 
we also computed the effect at $45^{\circ} \mathrm{N}$ and $90^{\circ} \mathrm{E}$ (i.e. near the west end of the Altai Mountains in Mongolia), and obtained a value of $0.027 \mu \mathrm{Gal}$.

In our case, using the 3.2 years of SST data, the range of the temporal variations of the unconserved steric height is about $2 \times 10^{-3} \mathrm{~m}$ in peak-to-peak magnitude. This would produce an error of about $\pm 0.1 \mu \mathrm{Gal}$ in our estimation of the SSH vectors if the volume correction is ignored. As seen in Fig. 5, the amplitude and phase of the most favorable annual $\mathrm{SSH}$ vector at Esashi are about $0.4 \mu \mathrm{Gal}$ and $-70^{\circ}$, respectively. An error of $\pm 0.1 \mu \mathrm{Gal}$ therefore corresponds to $25 \%$ of the estimated annual amplitude and it makes a difference of about $\pm 20^{\circ}$ in the estimated phase. It is true that this error will not be reflected uniformly in the estimated annual amplitude, but it remains evident that treatment of the total mass of the ocean cannot be ignored.

Related to the mass conservation, the IB correction for the atmospheric pressure changes applied to the $\mathrm{T} / \mathrm{P}$ data may be also an error source. This is because the error in the estimation of the spatial mean pressure over the ocean has a similar effect to the correction for the mass conservation. According to Wunsh and Stam- mer (1997), the spatial mean of the pressure changes over the ocean has a dominant periodic component of 1 year and its amplitude is about $1.2 \pm 0.54 \mathrm{hPa}$. The error of $0.54 \mathrm{hPa}$ (i.e. $5.4 \times 10^{-3} \mathrm{~m}$ in height change of the ocean) corresponds to an estimation error of about $0.26 \mu \mathrm{Gal}$ at Esashi at the most.

Further study including the problem of the hydrologic cycle and the mass (or volume) conservation is needed in order to clarify the meaning of the difference between the POCM and T/P shown here.

\subsection{Possible gravity changes due to the time variation of SSH}

The EOFs evaluated from the SSH data corrected for the steric effect reveal an ENSO-like oscillation which clearly appears in the third mode (see Fig. 2c). We have investigated by applied the EOF analysis to the gravity variations obtained from the SSH data corrected for the steric effect, and we recognized a seesaw-like oscillation also appears most clearly in the third mode. However, it is not straightforward to infer the time variations in the amplitude of gravity changes from the EOF analysis. We therefore
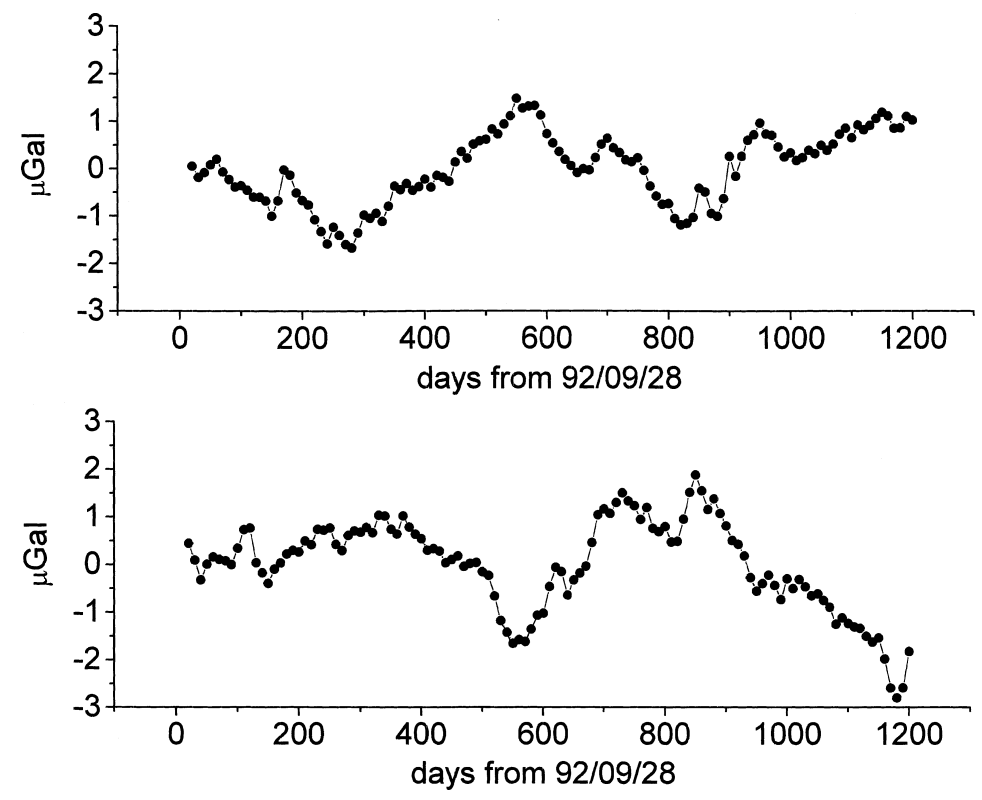

Fig. 7. Gravity changes expected from the ENSO-like ocean oscillation. Two computation results for the equatorial region of the Pacific Ocean are displayed. Top: west coast of Equador $\left(2.0^{\circ} \mathrm{N}\right.$ and $\left.280.1^{\circ} \mathrm{E}\right)$ as an example of the east side of the Pacific Ocean; bottom: Halmahera in north Moluccas $\left(1.5^{\circ} \mathrm{N}\right.$ and $\left.128.6^{\circ} \mathrm{E}\right)$ as an example of the west side. 
calculated the time series of gravity changes at land sites in the equatorial zone in the Pacific Ocean using the corrected POCM SSH data. The results are shown in Fig. 7. In this figure, the two computation results at $1.5^{\circ} \mathrm{N}, 128.6^{\circ} \mathrm{E}$ (Halmahera, north Moluccas) and $2.0^{\circ} \mathrm{N}, 280.1^{\circ} \mathrm{E}$ (the west coast of Ecuador) are shown as typical examples for the gravity changes on the west and east sides of the Pacific Ocean. A seesaw-like gravity changes between the west and east sides are shown in Fig. 7. The expected gravity changes reach a magnitude of about 2-3 $\mathrm{Gal}$ peak-to-peak. We computed the gravity changes at Bandung, Indonesia which is one of the observation sites of the GGP-Japan network, and found that a gravity change similar in both the amplitude and phase is also expected there.

Although some of the above SSH variations are considered to be contaminated by variations due to baroclinic currents which should cause no gravity changes, the remaining predicted gravity changes may be of sufficient magnitude to be detectable by the recent generation of absolute gravimeters, by careful observations with a superconducting gravimeter network such as GGP (Crossley et al., 1999) and by a satellite gravity mission such as Gravity Recovery and Climate Experiment (GRACE, which is a satellite gravity mission scheduled for launch in 2001 in a joint project of the USA and Germany). Because gravity is sensitive to mass changes, the use of gravity observations to constrain the magnitude of ocean mass changes, including the effect of the ENSO-like oscillation described here, is also important for understanding the effect of SSH variations on the polar motion of the earth.

\section{Conclusions}

Using the two sets of the data for SSH variations, we have estimated the effects of the SSH variations on the gravity observations. We employ a steric coefficient of $0.60 \times 10^{-2} \mathrm{~m} /{ }^{\circ} \mathrm{C}$ which has been determined as an average over the central parts of the Pacific and Atlantic Oceans. The observed annual gravity changes at three SG sites (Esashi, Japan, Canberra, Australia and Syowa Station, Antarctica) were compared with predicted gravity changes which were evaluated by taking into account the effects of the solid tide, ocean tide, polar motion and SSH variations. The results of the comparison suggest that, at all three sites, more than $80 \%$ of the annual gravity changes can be explained as the sum of these four effects. The important points here are that the effect of SSH variation needs to be included to explain the observed annual changes, and that the gravity observations made at the mid-latitudes favor a steric coefficient around $0.60 \times 10^{-2} \mathrm{~m} /{ }^{\circ} \mathrm{C}$ which was obtained independently from the relation between the SSH and SST.

The present results suggest that the observed annual gravity changes could be reproduced at an accuracy of the order of $0.1 \mu \mathrm{Gal}$. This also indicates that there is a possibility of studying the excitation and damping of the Chandler component using gravity data which is long enough to separate the Chandler and annual components. It is important in this application to carefully reduce the offsets occurring in the observed SG data. In order to reduce the ambiguity in the analysis due to the effect of offsets, it is desirable to maintain the sensitivity and the calibration of the gravity record by comparison with an absolute gravimeter at least twice a year.

We have not treated here the effect of the hydrologic cycle on the earth's surface. However, this effect may need to be considered to explain the systematic differences in amplitude and phase between the SSH vectors which were evaluated from the two datasets, the POCM and the T/P. Related to this, we also need to revisit the problem of the mass conservation in the oceans.

\section{Acknowledgements}

The POCM SSH and T/P data were provided by Naval Post-Graduate School (NPS) of USA. SST data were kindly offered by Robin Tokmakian of NPS. The SG data used here were obtained from the GGP-Japan network, which is being operated under the support of ocean Hemisphere Project conducted by Fukao of Earthquake Research Institute, University of Tokyo (Grant-in-Aid for Scientific Research no. 09NP1101 of the Ministry of Education, Science and Culture). The observation at Canberra is continued under a cooperative project between National Astronomical Observatory, Japan (NAO) and the Research School of Earth Sciences of the Australian National 
University. The scale factor of the SG at Canberra was calibrated in September 1998 with the assistance of Mike Gladwin of the Division of Exploration and Mining of the Commonwealth Scientific and Industrial Research Organization (CSIRO). The observation at Syowa is maintained by the wintering parties of Japanese Antarctic Research Expedition. The SG observations could not continue without their support. This study was partly support by a Grant-in-Aid for the Cooperative Research Program of NAO (nos. 9705, 9805 and 9905).

We thank the referees who critically read the manuscript. Their comments were very helpful to revise the manuscript.

\section{References}

Agnew, D.C., 1983. Conservation of mass in tidal loading computations. Geophys. J. R. Astr. Soc. 72, 321-325.

Aoyama, Y., Nawa, K., Yamamoto, H., Doi, K., Shibuya, K., Sato, T., 1997. Calibration of the SG at Syowa Station using an absolute gravimeter FG5. In: Kaminuma, K., Imanishi, Y. (Eds.), Proceedings of the 6th Workshop on SG, pp. 48-49 (in Japanese)

Bretherton, C.S, Smith, C., Wallace, J.M., 1992. An intercomparison of methods for finding coupled patterns in climate data. J. Climate 5, 541-560.

Crossley, D., Hinderer, J., Casula, G., Francis, O., Hsu, H.-T., Imanishi, Y., Jentzsch, G., Kaarrianen, J., Merriam, J., Meurers, B., Neumeyer, J., Richter, B., Shibuya, K., Sato, T., van Dam, T., 1999. Network of superconducting gravimeters benefits a number of disciplines. EOS, Trans. Am. Geophys. Union 80 11 (121), 125-126.

Dehant, V., Zschau, J., 1989. The effect of mantle inelasticity on tidal gravity. Geophys. J. 97, 549-555.

Delcourt-Honorez, M., 1986. Earth tides response and barometric effect in three well-aquifer systems. The effect on gravity of the water-level variations. In: Viera, R. (Ed.), Proceedings of the 10th International Symposium on Earth Tides, pp. 843-854.

Doi, K., 1993. Estimation of gravity change induced by variation of sea surface topography. In: Ishii, H., Takemoto, S. (Eds.), Proceedings of the CRCM'93, Kobe, pp. 359-362.

Farrell, W.E., 1972. Deformation of the earth by surface loads. Rev. Geophys. Space Phys. 10, 761-797.

Farrell, W.E., 1973. Earth tides, ocean tides and tidal loading. Philos. Trans. R. Soc. London, Ser. A. 274, 253-259.

Goodkind, J.M., 1999. The superconducting gravimeter. Rev. Sci. Instrum. 70 (11), 4131-4152.

Greatbatch, R.J., 1994. A note on the representation of steric sea level in models that conserve volume rather than mass. J. Geophys. Res. 99 (6), 12767-12771.

Ito, K., Ikami, A., Shibuya, K., Kaminuma, K., Shibuya, 1984. Upper crustal structure beneath the Ongul Islands, east Antarctica. Mem. Natl. Inst. Polar Res. Ser. C15, 3-12.
Johnson, T.J., Wilson, C.R., Chao, B.F., 1999. Oceanic angular momentum variability estimated from the Parallel Ocean Climate Model 1988-1998. J. Geophys. R. 104 (B11), 25183 25195.

Kaneko, Y., Sato, T., Sasao, T., 1974. Periodic variation of earth's gravity due to the polar motion and possibility of its observational detection by means of absolute gravimetry. Proc. Int. Latit. Obs. Mizusawa 14 (14), 24-25.

Leuliette, E.W., Wahr, J.M., 1999. Coupled pattern analysis of sea surface temperature and TOPEX/Poseidon sea surface height. J. Phys. Oceanogr. 29, 599-611.

Loyer, S., Hinderer, J., Boy, J., 1999. Determination of the gravimetric factor at the Chandler period from earth orientation data and superconducting gravimeter observations. Geophys. J. Int. 136, 1-7.

Mukai, A., Higashi, T., Takemoto, S., Nakagawa, I., Naito, I., 1995. Accurate estimation of atmospheric effects on gravity observations made with a superconducting gravity meter at Kyoto. Phys. Earth Planet Int. 91, 149-159.

Mukai, A., Takemoto, S., Fukuda, Y., Higashi, T., Tanaka, T., 1999. Effect of the change in underground water on determination of the parameters of pole tide at Kyoto. In: Kaminuma, K., Imanishi, Y. (Eds.), Proceedings of 9th Workshop on SG, pp. 56-59 (in Japanese).

National Geophysical Data Center, 1988. ETOPO-5 bathymetry topography data. Data Announc. 88-MGG-02, National Oceanic and Atmospheric Administration, US Department of Commerce, Boulder, CO.

Ponte, R.M., 1999. A preliminary model study of the large-scale seasonal cycle in bottom pressure over the global ocean. J. Geophys. R. 104 (C1), 1289-1300.

Ponte, R.M., Stammer, D., 1999. Role of ocean currents and bottom pressure variability on seasonal polar motion. J. Geophys. R. 104 (C10), 23393-23409.

Preisendorfer, R.W., Mobely, C., 1988. Principal Component Analysis in Meteorology and Oceanography. Elsevier, Amsterdam, $425 \mathrm{pp}$.

Press, W.H, Flanney, B.P., Teukolsky, S.A., Vetterling, W.T., 1989. Numerical recipes. In: The Art of Scientific Computing. Cambridge University Press, Cambridge, 818 pp.

Richter, B., 1990. The long period elastic behavior of the earth. In: McCarthy, D.D., Carter, W.E. (Eds.), Geophys. Monogr IUGG, Vol. 9. Variation in Earth Rotation, pp. 21-25.

Sato, T., Hanada, H., 1984. Computer program 'GOTIC' for the computation of oceanic tidal loading effects. Publ. Int. Latit. Obs. Mizusawa 18, 29-47.

Sato, T., Tamura, Y., Kikuchi, N., Naito, I., 1990. Atmospheric pressure effect on gravity observation and its application to geophysical problems. In: Sato, T., Ooe, M., Ida, Y. (Eds.), Proceedings of the Workshop on the Earth's Central Core, pp. 27-31 (in Japanese).

Sato, T., Tamura, Y., Okubo, S., Yoshida, S., 1996. Calibration of the scale factor of superconducting gravimeter at Esashi using an absolute gravimeter FG5. J. Geodetic Soc. Jpn. 42 (4), 225-232.

Sato, T., Nawa, K., Shibuya, K., Tamura, Y., Ooe, M., Kaminuma, K., Aoyama, Y., 1997. Polar motion effect on gravity observed 
with a superconducting gravimeter at Syowa Station, Antarctica. In: Segawa, J., Fujimoto, H., Okubo, S. (Eds.), Proceedings of the International Association of Geodesy Symposia, Vol. 117, pp. 99-106.

Sato, T., Takemoto, S., Imanishi, I., 1999. GGP and GGP-Japan network. In: Kaminuma, K. (Ed.), Superconducting Gravimeter Network. Chikyu Monthly 21 (8) 474-477 (in Japanese).

Semtner, A.J., Chervin, R.M., 1992. Ocean general circulation from a global eddy-resolving model. J. Geophys. R. 97, 5493-5550.

Shapiro, R., 1970. Smoothing, Filtering, and Boundary Effects. Review of Geophys. and Space Phys. 8 (2), 359-387.

Stammer, D., 1997. Steric and wind-induced changes in TOPEX/POSEIDON large-scale sea surface topography observation. J. Geophys. Res. 102 (C9), 20987-21009.

Stammer, D., Tokmakian, R., Semter, A., Wunsh, C., 1996. How well does a $1 / 4^{\circ}$ global circulation model simulate large-scale oceanic observations? J. Geophys. Res. 101 (C10), 2577925811.

Takanezawa, T., 1998. Dynamical response of global ocean to long period tidal force. Ph.D. Thesis.

Tamura, Y., 1987. A harmonic development of the tied-generating potential. Marees Terrestres Bull. d'Inform. 99, 6813-6855.
Tamura, Y., Sato, T., Ooe, M., Ishiguro, M., 1991. A procedure for tidal analysis with a Bayesian information criterion. Geophys. J. Int. 104, 507-516.

van Dam, T.M., Francis, O., 1998. Two years of continuous measurements of tide and nontidal variations of gravity in Boulder, Colorado. Geophys. Res. Lett. 1.25 (3), 393-396.

Wahr, J.M., 1981. Body tides of an elliptical, rotating, elastic and oceanless earth. Geophys. J. R. Astr. Soc. 64, 677-703.

Wahr, J.M., 1985. Deformation induced by polar motion. J. Geophys. R. 90 (B11), 9363-9368.

Wahr, J.M., Bergen, Z., 1986. The effect of mantle anelasticity on nutations, earth tides, and tidal variation in rotation rate. Geophys. J. R. Astr. Soc. 87, 633-668.

Warburton, R., Brinton, E., 1995. Recent developments in GWR Instruments Superconducting Gravimeters. In: Potvin, C. (Ed.), Proceedings of the 2nd Workshop on Non-Tidal Gravity Changes. Concel de Europe Cahiers du Centre Europeen de Geodynamique et de Seismologie, Vol. 11, pp. 23-56.

Wunsh, C., Stammer, D., 1997. Atmospheric loading and the oceanic 'inverted barometer' effect. Rev. Geophys. 35 (1), 79 107. 